\title{
Modulatory effects mediated by metabotropic glutamate receptor 5 on lateral geniculate nucleus relay cells
}

\author{
Carmen de Labra, Casto Rivadulla and Javier Cudeiro
}

\begin{abstract}
Glutamate is thought to be the excitatory neurotransmitter in the lateral geniculate nucleus (LGN) of the cat, mediating visual transmission from the retina via ionotropic receptors of both d,l- $\alpha$-amino-3-hydroxy-5- $\alpha$-methyl-4isoxazolepropionate and $N$-methyl-d-aspartate subtypes. Moreover, glutamate also exerts an important modulatory influence on LGN cells, where metabotropic glutamate receptors (mGluRs) seem to play a crucial role. Here we show in anesthetized adult cats that iontophoretic application of the specific mGluR5 antagonist 2-methyl-6(phenylethynyl)-pyridine (MPEP) produced two, distinctly different, effects on LGN neurons. Visual responses to flashing spots and drifting gratings were attenuated (decreased by an average of 59\%) in 13 of 23 of the cells but augmented (increased by an average of $60 \%$ ) in 10 of 23 of the cells. Further, in each case when the specific mGluR5 agonist (R,S)-2-chloro-5-hydroxyphenylglycine was applied, the effects obtained were the opposite to those of MPEP. Data obtained in a second group of experiments to determine a possible interaction between mGluR5 blockade by MPEP and glutamate ionotropic receptors show that, in the majority of neurons (11 of 15, 73\%), the MPEP-mediated effects seem to be independent of $N$-methyl-d-aspartate and d,l- $\alpha$-amino-3-hydroxy-5- $\alpha$-methyl-4isoxazolepropionate receptor activity. Our results demonstrate a physiological role for mGluR5 in controlling retinal input and show, in vivo, a more intricate scenario than previously suggested, highlighting the complexity of metabotropic receptor interactions with excitatory and inhibitory elements in the thalamus.
\end{abstract}

Keywords: : cat, glutamate, metabotropic receptors, 2-methyl-6-(phenylethynyl)-pyridine, retinal input, vision

\section{Introduction}

Metabotropic glutamate receptors (mGluRs) have various modulatory functions in the central nervous system (Pin \& Duvoisin, 1995; Conn \& Pin, 1997; Anwyl, 1999). There are eight mGluR subtypes that are further segregated into three groups based on their sequence homology, pharmacology and coupling to second messenger systems (Pin \& Duvoisin, 1995; Conn \& Pin, 1997). The group I mGluRs (mGluR1 and R5) couple to phospholipase C and inositol-1,4,5 trisphosphate turnover, while group II (mGluR2 and R3) and group III (mGluR4, R6, R7 and R8) negatively couple to cAMP turnover (Pin \& Duvoisin, 1995; Conn \& Pin, 1997). The role of mGluRs in synaptic transmission and plasticity depends on their coupling activity and their pre- and postsynaptic localization (Martin et al., 1992; Petralia et al., 1996; Shigemoto et al., 1996, 1997; Li et al., 1997). Group II and III mGluRs are presynaptic autoreceptors controlling glutamate release (Glaum \& Miller, 1993; Burke \& Hablitz, 1994; Gereau \& Conn, 1995; Lovinger \& McCool, 1995; Sanchez-Prieto et al., 1996; Schrader \& Tasker, 1997; Anwyl, 1999; Bradley et al., 2000; Dube \& Marshall, 2000), while group I mGluRs play a role in regulating neuronal excitability and in facilitating LTP and LTD at both pre- and postsynaptic levels (Herrero et al., 1992; Sanchez-Prieto et al., 1996; Anwyl, 1999; Bortolotto et al., 1999; Manahan-Vaughan et al., 1999.; Schwartz \& Alford, 2000; Chuang et al., 2001; Lee AC et al., 2002; Lee O et al., 2002; Gubellini et al., 2003) and also in potentiating $N$-methyl-d-aspartate (NMDA) (Doherty et al., 1997; Alagarsamy et al., 1999; Salt \& Binns, 2000; Pisani et al., 2001; Benquet et al., 2002) and d,l- $\alpha$-amino-3-hydroxy-5- $\alpha$-methyl-4isoxazolepropionate (AMPA) receptor-mediated responses (Ugolini et al., 1999).

Recent work from our group on lateral geniculate nucleus (LGN) physiology has focused on the modulatory influence of the group I receptors, demonstrating that a fundamental component of this influence comes from the cortex and is mediated by mGluR1 (Rivadulla et al., 2002). Here, we aimed to explore the functional role of mGluR5. Interestingly, it has been shown that mGluR5 are spatially segregated from mGluR1 and are primarily located postsynaptically to retinal inputs in dendritic terminals of GABAergic interneurons (Godwin et al., 1996). This suggests a different role for mGluR5 within the 
cat's LGN, related to the incoming signal from the retina. It has been shown, in a series of elegant studies in vitro, that activation of mGluR receptors (presumably mGluR5) activate dendritic terminals inhibiting the postsynaptic LGN relay cell (Cox et al., 1998; Cox \& Sherman, 2000). Therefore, we felt it logical to use an in vivo preparation to study the functional roles of mGluR5 in visually elicited responses and how LGN cells are affected by pharmacological manipulation of these receptors. We have taken advantage of the mGluR5 agonist (R,S)-2-chloro-5-hydroxyphenylglycine (CHPG) and antagonist 2-methyl-6(phenylethynyl)-pyridine (MPEP) (Doherty et al., 1997; Gasparini et al., 1999; Salt et al., 1999; Spooren et al., 2001).

The data obtained revealed a more complex situation, on one hand confirming the putative role of mGluR5 in inhibitory control, inhibiting some relay cells, while, on the other hand, mGluR5 activation seemed able to up-regulate the visual excitability of other LGN relay cells, possibly by a mechanism involving NMDA and AMPA receptors.

\section{Materials and methods}

\section{Animal preparation}

Experiments were performed on adult cats of either sex. Animals were anesthetized with halothane in nitrous oxide (70\%) and oxygen (30\%) (halothane, 5\% for induction, 1.5-2\% for surgery and $0.1-0.5 \%$ for maintenance). To prevent eye movements, animals were paralyzed with gallamine triethiodide (loading dose, $40 \mathrm{mg}$, maintenance, $10 \mathrm{mg} / \mathrm{kg} / \mathrm{h}$ i.v. infusion). The end-tidal $\mathrm{CO}_{2}$ levels, electrocardiogram waveform, intersystolic interval and frequency of spindles in the electroencephalogram were monitored continuously throughout the experiment. The rate and depth of artificial respiration were adjusted to maintain end-tidal $\mathrm{CO}_{2}$ at 3.8-4.2\%; the level of halothane was chosen to achieve a state of light anesthesia. Once a stable state was reached, any variation in the monitored parameters commensurate with a change in the depth of anesthesia was compensated for by alterations in the level of halothane. Wound margins were treated with lidocaine hydrochloride with epinephrine administered subcutaneously. Ear bars were coated with lidocaine gel. The eyes were treated with atropine methonitrate and phenylephrine hydrochloride, protected with zero power contact lenses and brought to focus on a semiopaque tangent screen $57 \mathrm{~cm}$ distant. Visual stimuli were viewed monocularly through 3$\mathrm{mm}$ artificial pupils. To further reduce possible eye movement artifacts, posts were fixed to the sclera. The procedures conformed to the guidelines of the Spanish Physiology Society, International Council for Laboratory Animal Science and European Union (statute no. 86/809).

\section{Recording and iontophoretic application of drugs}

Seven-barrelled micropipettes were used for iontophoretic ejection of drugs and single unit extracellular recording in the A laminae of the cat dorsal LGN. Drug barrels contained a selection of the following solutions: $\mathrm{NaCl}$ (3 m for recording), NMDA (0.1 m, pH 8.0), AMPA (10 mm in $75 \mathrm{~mm} \mathrm{NaCl,}$ $\mathrm{pH}$ 8.5), ACh (1 m, pH 5), MPEP (10 mm in $150 \mathrm{~mm} \mathrm{NaCl}, \mathrm{pH}$ 5) CHPG (100 mm, pH 8) or pontamine sky blue ( $2 \% \mathrm{w} / \mathrm{v}$ in $0.5 \mathrm{~m}$ sodium acetate solution for histological reconstruction). ACh was included in the pipette for identifying relay cells on the basis of its excitatory effect (McCormick \& Prince, 1987). Pipette tips were broken back to diameters ranging from 5 to $10 \mu \mathrm{m}$ and each drug barrel was subject to a retention current of 5-25 nA of appropriate polarity. Ejecting DC currents were in the range of 30$100 \mathrm{nA}$. A barrel with $1 \mathrm{~m} \mathrm{NaCl}$ was used for current balancing.

\section{Visual stimulation and experimental design}

Cells were carefully classified by a battery of tests into X and Y groups of ON and OFF subtypes. Particular emphasis was placed on the linearity of spatial summation in the responses to sinusoidal gratings of the appropriate spatial frequency. Sinusoidally phase-reversed gratings were presented at a number of spatial phase positions in a randomized interleaved sequence, using the highest spatial frequency giving reliable responses. Fourier analysis produced first and second harmonic components of these responses, which were plotted against spatial phase. $\mathrm{X}$ cell responses were characterized by a strongly phase-dependent first harmonic which exhibited a clear null point while $\mathrm{Y}$ cell responses included a second harmonic component which was not strongly phase dependent. Other tests included the duration of the response to standing contrast over the receptive field center, the presence or absence of a shift effect, the strength of surround antagonism and size of receptive field center for a given eccentricity (Enroth-Cugell \& Robson, 1966; Cleland et al., 1971; Derrington \& Fuchs, 1979). Waveforms and time 
stamps were stored (Plexon Inc., USA) and we performed offline spike sorting in order to assess the isolation of the selected spike and recording stability. Computer-controlled visual stimuli (Lohmann Research Equipment, Germany) were presented monocularly on a monitor with a mean luminance of $14 \mathrm{~cd} / \mathrm{m}^{2}$ at a contrast of 0.6 , refresh rate $128 \mathrm{~Hz}$. Visual stimuli consisted of sinusoidal drifting wave gratings and spots of different size flashing on the receptive field. The spatiotemporal properties of the stimuli were optimally set for each cell. Receptive fields were mapped by forward correlation with sparse noise (Rivadulla et al., 2003). The stimulus space was divided into a $20 \times 20$ grid (grid spacing ranged from 8 to $20^{\circ}$ ). In a given stimulus run, a series of black or white squares were flashed singly for a brief period of time (30 ms) at each location on the grid in pseudo-random order. The multihistogram technique was used for quantitative assessment of receptive field parameters. Our basic experimental paradigm involved establishing control responses to a range of visual stimuli. Responses were collected for the entire duration of the stimulus and were averaged over 10-15 presentations. For drifting gratings, each presentation included 10 cycles of the stimulus. This was then repeated during continuous iontophoretic application of the drug of interest. Throughout the study, action potentials were timed and counted using the Plexon system. Data were analysed by plotting peristimulus time histograms from these recordings. Spikes obtained in both conditions (control/drug ejection) were compared after background activity was subtracted. Background activity was obtained from the presentation of blank stimulus (screen with mean luminance) intermixed with visual stimuli.

In another set of experiments aimed at examining the possible interactions of MPEP with ionotropic glutamate receptors, we used pulsatile iontophoretic application of NMDA and AMPA before and during continuous application of MPEP (no visual stimulation was used during these experiments). Typically, responses were averaged over several cycles and were assessed from the accumulated count in the binned peristimulus time histograms. Data from individual neurons were used to compute mean values of effects. Statistical comparisons of these values under control conditions and during drug applications were made using the Wilcoxon signed rank test. Results were deemed to be significant when $P<0.05$.

\section{Results}

The results presented in this work were obtained from neurons recorded in the A laminae of the LGN of adult cats whose receptive fields were within $12^{\circ}$ of the area centralis.

Effects of 2-methyl-6-(phenylethynyl)-pyridine (metabotropic glutamate receptor 5 antagonist) and (R,S)2-chloro-5- hydroxyphenylglycine (metabotropic glutamate receptor agonist) on visually driven activity

Thirty cells (12 X, $16 \mathrm{Y}$ and two unclassified) were successfully studied using a combined visual stimulation and pharmacological protocol. Twenty-three (77\%) of these cells showed a statistically significant modification of their visually-evoked responses when MPEP was ejected. In these neurons ACh application produced a clear increment in background firing and they were therefore considered to be relay cells. To our surprise, the observed effect was not consistent but could be split into two distinct categories.

(i) Cells showing a decrement in response to visual stimulation under continuous MPEP ejection (13 of 23, 57\%). This can be observed in Fig. 1 where the response of a Y ON LGN cell to a drifting sinusoidal grating of optimal spatial and temporal frequency (inset) before, during and after the ejection of MPEP is illustrated. MPEP clearly reduced (43\%) the response obtained with visual stimulation. After a recovery period (20 min) CHPG (specific agonist of mGluR5 receptors) was tested on the same cell. CHPG ejection caused the opposite effect and an increment (96\%) in cell response to visual stimulation was obtained. When CHPG was ejected simultaneously with MPEP, the excitatory effect of the agonist was partially blocked, showing a specific effect mediated by mGluR5. We also used a different type of visual stimulus, flashing spots of appropriate polarity, covering the receptive field. This is shown in Fig. 2. On the left, the control response obtained with two consecutives flashes (inset) is illustrated for an X ON neuron. After a control response was obtained (10 trials), in this case CHPG was first iontophoretically applied, which resulted in a clear increment (44\%) of the visually-evoked responses. Once the cell recovered (15 min, not shown), MPEP was applied and, as expected, the opposite effect was obtained, with a drop in visual responses of $47 \%$. After a further 25 min, the cell recovered. This type of result was found consistently in all 13 cells [five X, seven Y, one unclassified; average decrement $59 \pm 10 \%$ (SEM) with MPEP; average increment $68 \pm 19 \%$ with CHPG], with no obvious differences between cell types. The background firing of these cells was similarly modulated by the applied compounds (average decrement $64 \pm 10 \%$ with MPEP; average increment $88 \pm 20 \%$ with CHPG). 
(ii) Cells showing an increased response to visual stimulation in the presence of MPEP (10 of 23, 43\%). A typical example is shown in Fig. 3. We show here the response from a Y ON LGN cell to a drifting sinusoidal grating of optimal spatial and temporal frequency (inset) before, during and after the ejection of MPEP. Blocking mGluR5 significantly augmented the visual response, which recovered to control levels after approx. 20 min (data not shown). Figure 4 shows another example (X OFF) of a cell, here stimulated with drifting gratings and flashing spots. Figure 4A represents the visual response to several cycles of the grating. When MPEP was continuously ejected (5 min, middle histogram), the visual response was augmented by about 45\%. Conversely, CHPG application induced a drop in cell firing ( 23\%). Figure 4B shows the effect obtained on the same cell when the visual stimulus used was a flashing spot. Again, the response of the cell increased under continuous ejection of MPEP. CHPG application produced the opposite effect. As with the previous group, these results were obtained in both $\mathrm{X}$ and $\mathrm{Y}$ cells (four $\mathrm{X}$ and six $\mathrm{Y}$; average increment $60 \pm 17 \%$ with MPEP; average decrement $45 \pm 13 \%$ with CHPG), with no obvious difference between cell types. As with the cells described above, the background firing of these cells was similarly modulated by the applied compounds (average increment $51 \pm 8 \%$ with MPEP; average decrement $44 \pm 16 \%$ with CHPG).

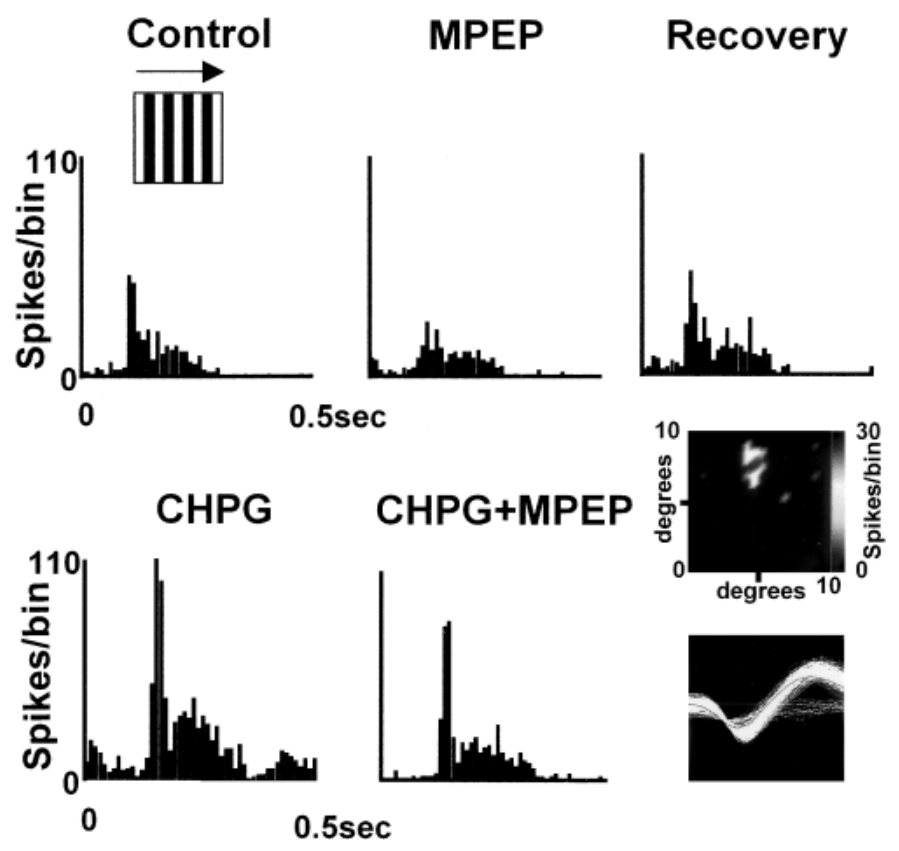

Figure 1 The effect of 2-methyl-6-(phenylethynyl)-pyridine (MPEP) and (R,S)-2-chloro-5-hydroxyphenylglycine (CHPG) application on the visual responsiveness of a single ON-center Y lateral geniculate nucleus cell. The stimulus is a full field drifting sinusoidal grating of optimal characteristics. The inset above the records here and in subsequent figures summarizes the stimulus situation in concept; they do not attempt to reflect the size of the stimulus or the actual spatial frequency. Peristimulus time histograms illustrate the response of the cell to the grating before (Control), in the presence of the specific metabotropic glutamate receptor (mGluR)5 antagonist MPEP (ejected iontophoretically using $60 \mathrm{nA}$ for $5 \mathrm{~min}$ ) and after a recovery period of 20 min. The records shown in the bottom panel document the response of the cell to the stimulus when the mGluR5 agonist CHPG was ejected alone (90 nA, $10 \mathrm{~s}$ ) and in the presence of MPEP (60 nA). Histograms were constructed from 15 presentations of the stimulus. Bin size, $10 \mathrm{~ms}$. The receptive field of the cell obtained with sparse noise (see Materials and methods) is shown in the lower right corner of the figure. The spike waveform is also shown.

Surprisingly, the two groups of cells both included both $\mathrm{X}$ and $\mathrm{Y}$ cells and we could find no distinguishing feature apart from their opposite responses to the applied mGluR5 (ant)agonist. In the two groups the effects of approximately equal potency were seen at similar ejection current levels. The level of spontaneous activity was similar between the two groups (39 \pm 12 and $42 \pm 16$ spikes per bin, respectively) and the proportion of spikes fired in bursts (an indicator of the physiological state of the preparation; Rivadulla et al., 2003) in control conditions was also similar (8 vs. 10\%, respectively). Cells in each group were found in the same animals, the same penetrations and with the same electrodes. 


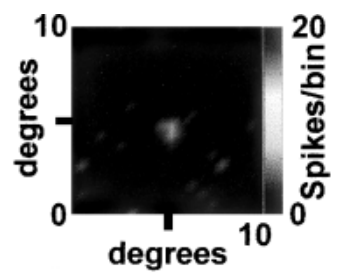

Control

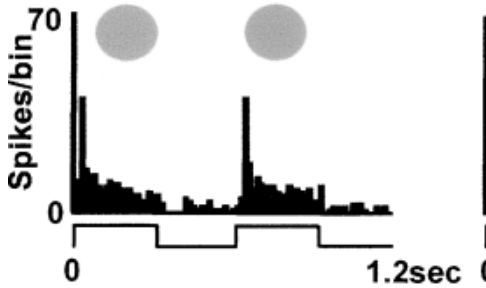

CHPG

MPEP
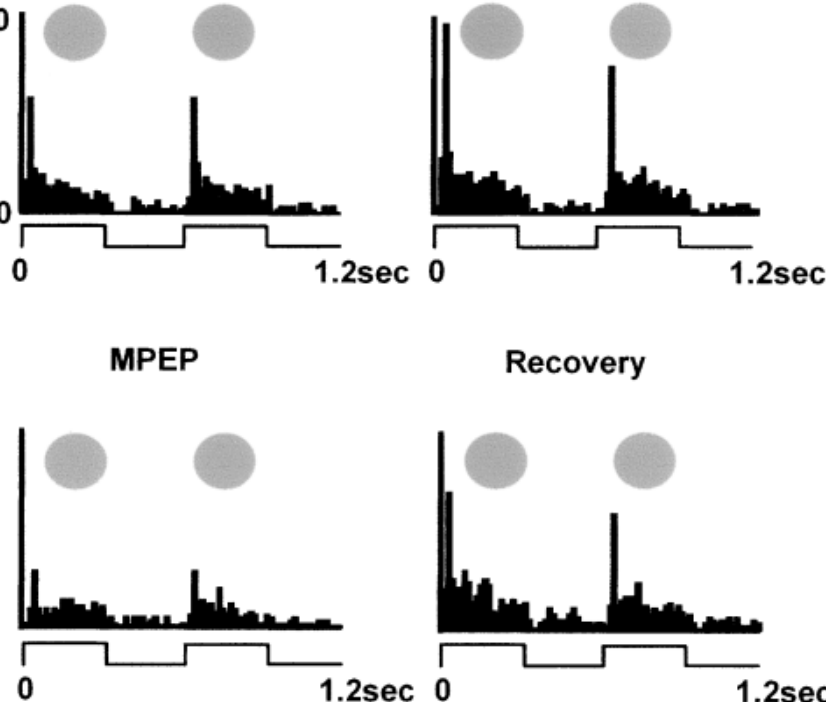

Recovery

( 2 The effect of 2-methyl-6-(phenylethynyl)-pyridine (MPEP) and (R,S)-2-chloro-5-hydroxyphenylglycine (CHPG) on visual responses obtained with flashing spots. Peristimulus time histograms (PSTHs) showing the response of a lateral geniculate nucleus cell (ON X) to flashed spots restricted to the receptive field center (inset above the PSTH) before (Control), during CHPG ejection and in the presence of MPEP. Recovery between CHPG and MPEP applications is not shown. Duration of the stimuli was $0.3 \mathrm{~s}$. Bin size, 10 ms. CHPG ejection, $80 \mathrm{nA}, 15 \mathrm{~s}$; MPEP ejection, $80 \mathrm{nA}, 4 \mathrm{~min}$. The representation of the stimulus has a merely graphic purpose and does not reflect its actual properties. The receptive field of the cell is also shown above the records.

\section{Control}

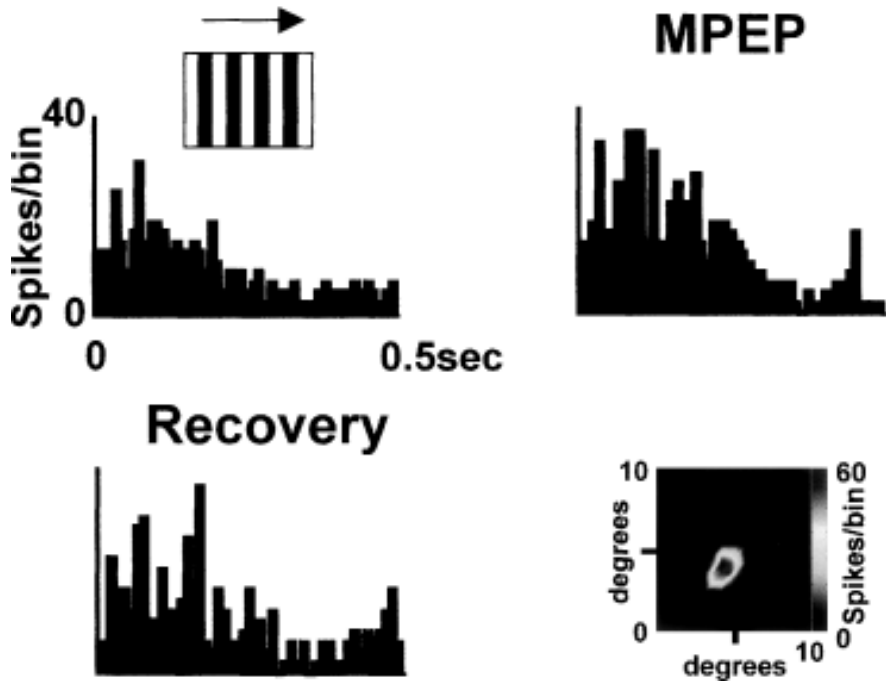

Figure 3. The metabotropic glutamate receptor 5 antagonist 2-methyl-6-(phenylethynyl)-pyridine (MPEP) also produced an increment in visually-evoked responses. Data refer to an ON Y lateral geniculate nucleus cell. 10 trials; MPEP ejection, $60 \mathrm{nA}$, $4 \mathrm{~min}$. Bin size, $10 \mathrm{~ms}$, average of 10 trials. Lower right corner, receptive field of the cell. 

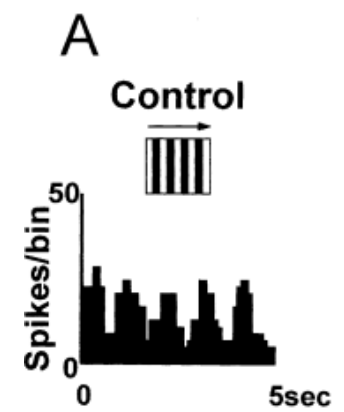

$\mathrm{B}$

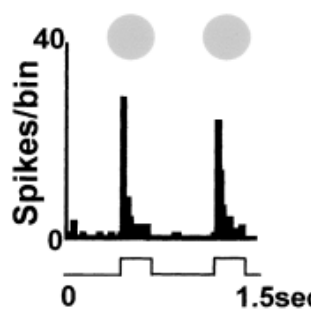

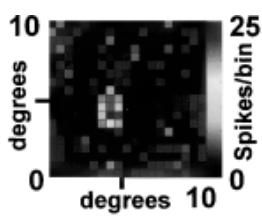

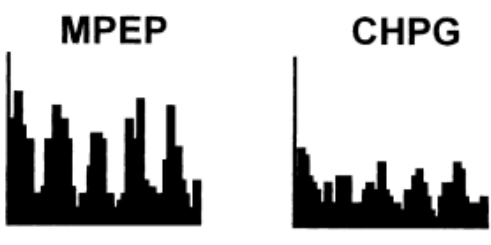

Figure 4. When 2-methyl-6-(phenylethynyl)-pyridine (MPEP) application increases responsiveness, (R,S)-2-chloro-5hydroxyphenylglycine (CHPG) produces the opposite. In this example the cell was studied with both a drifting grating and flashing spots as stimuli. (A) Peristimulus time histograms documenting the cell response to the grating (five cycles, 12 trials). Bin size, $50 \mathrm{~ms}$. (B) Response of the same cell to flashed spots. Bin size, $20 \mathrm{~ms}$. For simplicity recoveries are not shown. MPEP ejection, $60 \mathrm{nA}, 5 \mathrm{~min}$; CHPG ejection, $90 \mathrm{nA} 12 \mathrm{~s}$.

2-Methyl-6-(phenylethynyl)-pyridine and N-methyl-d-aspartate/d,l- $\alpha$-amino-3-hydroxy-5- $\alpha$-methyl-4isoxazolepropionate receptor-mediated responses

In order to study the effect of mGluR5 blockade and its possible interactions with glutamate ionotropic receptors present in the LGN, a series of pharmacological experiments without visual stimulation were conducted. We were able successfully to complete the experimental protocol (including recoveries) in 15 neurons. Responses of LGN neurons to NMDA and AMPA application were compared with those where MPEP was ejected simultaneously. Responses to regular iontophoretic ejection of agonists were recorded over several 5-min cycles before the ejection of MPEP. The antagonist was then continuously ejected for at least three agonist cycles and the MPEP ejection was terminated when a selective effect was seen or it was deemed that no effect was evident. Agonist ejection cycles were continued until recovery from the effects of MPEP was seen (12-17 min). We always obtained an excitatory response with the iontophoretic application of NMDA and AMPA. Under these conditions, in the majority of the cells $(n=11,73 \%)$ MPEP did not modify AMPA (during drug response equals $98 \pm 5 \%$ of control) and NMDA (during drug response equals $105 \pm 5 \%$ of control) mediated activity (see Fig. 5). Further, spontaneous activity was also unaffected in these cells. However, a small but significant number of cells $(n=4,27 \%)$ showed responses to AMPA and NMDA which were modulated by concurrent application of MPEP. In these neurons, the response to both NMDA and AMPA was significantly reduced (by $77 \pm 31 \%$ and $83 \pm 12 \%$, respectively). A representative example is shown in Fig. 6. All four cells were excited by the application of ACh and are therefore considered to be LGN relay cells. In three out of four of these cells, background activity was reduced in parallel with the effects on the excitatory amino acids (by $42 \pm 13 \%$ ) and the background activity of the remaining cell was unaffected. 


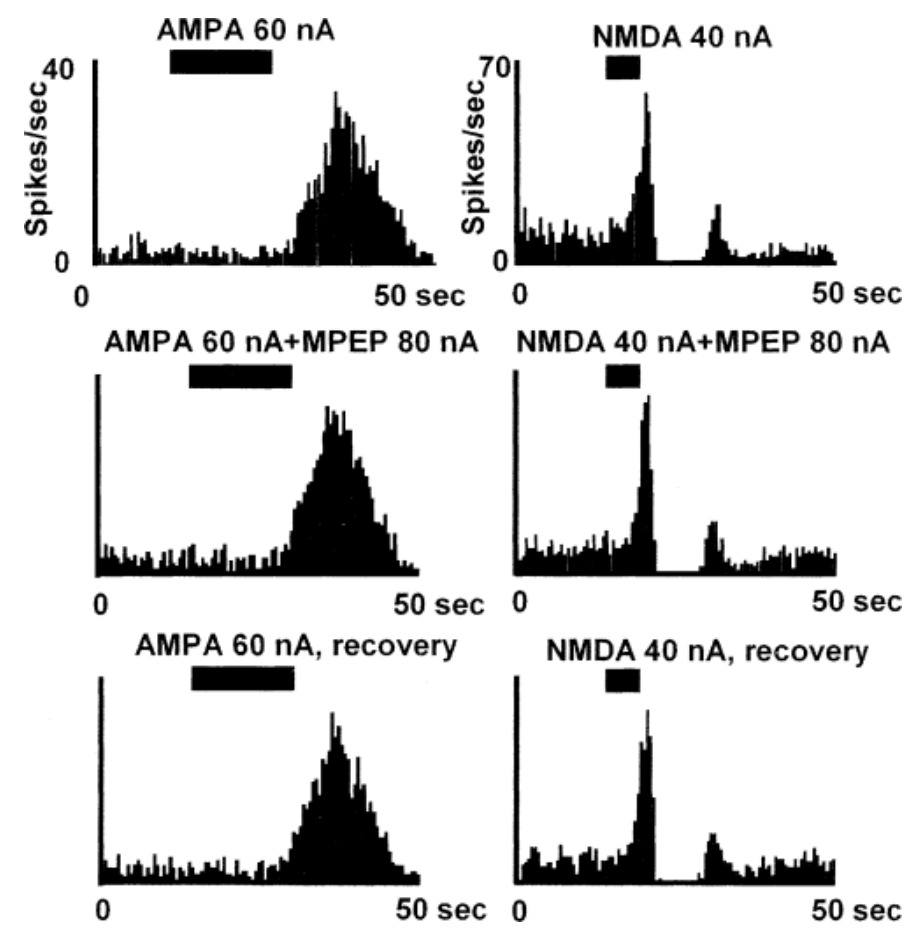

Figure 5. In the majority of the neurons, 2-methyl-6-(phenylethynyl)-pyridine (MPEP) applications did not change $N$-methyl-daspartate (NMDA) (right column) and d,l- $\alpha$-amino-3-hydroxy-5- $\alpha$-methyl-4-isoxazolepropionate (AMPA) (left column) mediated responses. Peristimulus time histograms from a single cell showing the excitatory response obtained with AMPA and NMDA ejected iontophoretically (marker bars above the records), during continuous MPEP ejection and after a recovery period of 15 min. Bin size, $500 \mathrm{~ms}$
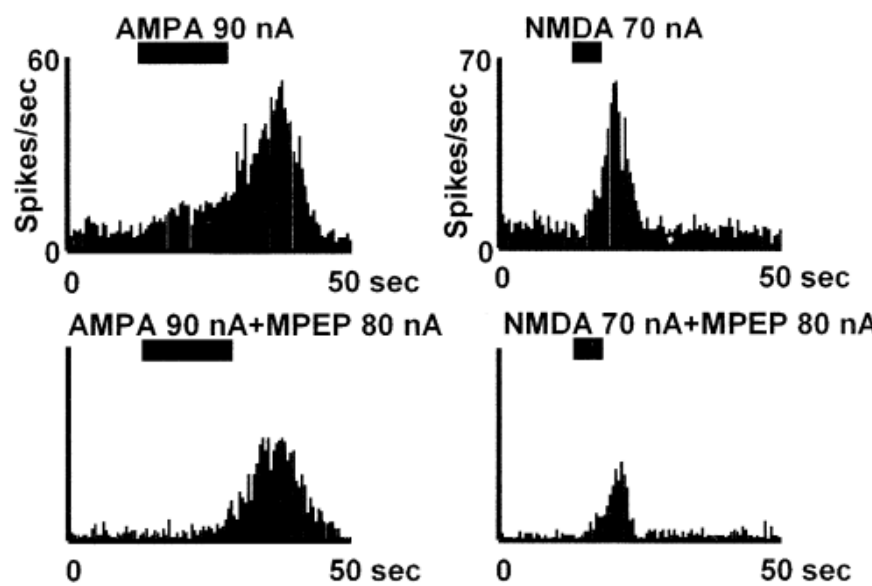

0

$50 \mathrm{sec}$

NMDA 70 nA, recovery

AMPA 90 nA, recovery
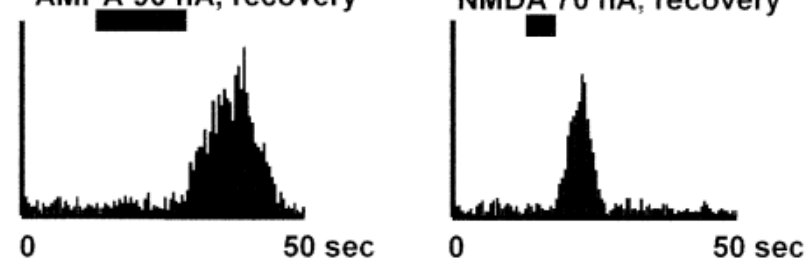

Figure 6. Effect of 2-methyl-6-(phenylethynyl)-pyridine (MPEP) on $N$-methyl-d-aspartate (NMDA) (right column) and d,l- $\alpha$ amino-3-hydroxy-5- $\alpha$-methyl-4-isoxazolepropionate (AMPA) (left column) evoked responses on another single cell (marker bars above the records). Note the reduction of NMDA and AMPA responses when these were coapplied with MPEP. Bin size, $500 \mathrm{~ms}$. 


\section{Discussion}

By combining electrophysiological, pharmacological and visual stimulation studies in the anesthetized cat, this study demonstrates, in vivo, the presence of functional mGluR5 receptors operating in the LGN. To a large extent our work corroborates previous findings obtained by Sherman's group which show that retinal synapses activate mGluRs (thought to be mGluR5) on F2 terminals (dendrites of LGN interneurons) promoting GABA release (Godwin et al., 1996; Cox et al., 1998). It may represent a control mechanism to prevent geniculate relay cells from saturating their responses under certain circumstances, e.g. during prolonged and intense visual stimulation (Cox et al., 1998). In this sense, our findings, where MPEP produced a clear increment in cell firing (and CHPG did the opposite), are clearly in favor of a role for mGluR5 involving this receptor in the control of GABA release. However, our data also provide a new and intriguing insight into the role of mGluR5 in the visual thalamus of the cat that we would like to discuss further.

\section{Modulatory effects of metabotropic glutamate receptor 5 in the lateral geniculate nucleus in vivo}

It is known that relay cells in the cat LGN receive synaptic input from a number of sources, with retinal input more focused toward the soma and cortical feedback located in the distal dendrites (Wilson et al., 1984; Erisir et al., 1997). GABAergic inhibitory inputs arise from both local inputs (both dendritic and axonal in nature) and from the overlying perigeniculate nucleus, the visual part of the thalamic reticular nucleus. These inhibitory inputs may interact locally with retinal or cortical input and specifically with retinal input in specialized structures called triads, where the inhibitory process receives direct input from the retinal synapse and, in turn, synapses on the relay cell. Such triads are most often found in the physiologically defined X cell type. Excitatory inputs may utilize different postsynaptic receptors, including both ionotropic and metabotropic (mGluR) families. By using CHPG and MPEP, agonist and antagonist, respectively, to mGluR5, we have found mGluR5-related activity in the two types of relay cells located in the A laminae of the LGN, namely X and Y. It is known that only X cells receive a significant number of F2 inputs (dendrites of interneurons) (Wilson et al., 1984). Therefore, in those neurons where the observed effect was an MPEP-induced increment of visually-evoked responses/background activity, the findings presented here fit with what is expected if we block mGluR5 located within triadic arrangements (typical of X cells; Wilson et al., 1984; Hamos et al., 1985, 1987). However, we also achieved the same type of effect in physiologically identified Y cells. In this case, as Y cells do not participate in triads, we suggest that the data can be explained by the fact that mGluR5 is also localized on terminals belonging to perigeniculate inhibitory interneurons (although less numerous) whose somas lie dorsal to the LGN (Godwin et al., 1996).

In our hands, MPEP also induced a reduction of cell firing in a significant number of cells. This effect cannot be explained in terms of GABA release as above. Two other, not mutually exclusive, possibilities may account for our findings.

(i) A possible explanation derives from the fact that group I mGluRs have a dual action on neurotransmitter release depending on the ambient concentration of glutamate. It has been shown in the hippocampus that these receptors are able to accommodate glutamate release to changes in the surrounding concentration of glutamate, switching from facilitation to inhibition of excitatory synaptic transmission (Rodriguez-Moreno et al., 1998). Similar results have been found in the rat cortex (Alagarsamy et al., 2002). From a mechanistic point of view, in our in vivo experiments we have to face a very complex situation, with all regulatory systems operating and affecting the physiology of the cells under study with visual stimulation and ejection of drugs. These manipulations must produce continuous modification of glutamate release affecting the extracellular milieu; concomitant changes of mGluR5 action (affecting GABA release) could also be expected. This hypothesis, although attractive, needs experimental confirmation in the cat LGN.

(ii) It has been shown by means of inmunohistochemistry that mGluR5 is prominently located in inhibitory F2 terminal profiles associated with the retinal input to LGN relay cells (Godwin et al., 1996). Nevertheless, it was also found that a small but significant proportion of profiles (13\%) labeled for mGluR5 but, crucially, not for GABA. These profiles are fine caliber dendrites that may correspond to relay cell distal dendrites in the cortical recipient zone (Godwin et al., 1996). Mechanistically, although this postsynaptic location of mGluR5 is not abundant, it may explain those effects in which MPEP reduced cell firing and CHPG increased visual responses. Despite in vitro studies carried out in the rat LGN (Turner \& Salt, 2000), which appeared to discard a role for mGluR5 in corticothalamic input, the level of complexity observed in vivo and in the cat makes us reluctant to completely reject this as a possibility. In several preparations, including the ventrobasal 
thalamus of the rat (a nucleus devoid of interneurons), mGluR5 has been shown to potentiate excitatory synaptic transmission through a postsynaptic action (Salt et al., 1999; Salt \& Binns, 2000) and has been implicated in sensory transmission. In our case, if, as suggested, the receptors are located on distal dendrites postsynaptically to corticofugal fibres, it is to be expected that MPEP application reduces cell firing. If so, it is tempting to speculate that in the cat LGN mGluR5 plays two different roles depending upon location. The first is related to the corticofugal feedback and is excitatory and the second modulates the level of inhibition and is associated with retinal input.

\section{Effects of 2-methyl-6-(phenylethynyl)-pyridine on ionotropic glutamate receptors}

Activation of mGluRs can modulate NMDA and AMPA receptor-mediated responses in a number of brain areas and cell types (for a review see Pin \& Duvoisin, 1995; Bordi \& Ugolini, 1999). On the other hand, although there is a general consensus in considering MPEP as a potent and selective antagonist of the mGluR5 subtype with no appreciable agonist or antagonist activity at recombinant mGluR1b, group II or III mGluRs or ionotropic glutamate receptors (Gasparini et al., 1999; Salt et al., 1999), some recent observations have raised questions about the receptor specificity of this selective antagonist and suggested caution in drawing conclusions about the role of mGluR5 based on the use of such compounds (O'Leary et al., 2000). For these reasons we felt that it was important to study the putative effect of MPEP on NMDA and AMPA responses. In the majority of cells our data showed that MPEP ejection produced no effect when applied simultaneously with the ionotropic agonists. However, it is worth noting that in $27 \%$ of neurons, all identified as relay cells, both NMDA and AMPA responses were clearly diminished by MPEP. We found no examples where the effect of NMDA/AMPA was increased by MPEP application. The exact mechanism by which ionotropic responses were affected is beyond the scope of our methods but it is important to note that the effects were seen at application current levels of MPEP no different to those used in the visual experiments as, although MPEP has been shown to have effects on NMDA- and AMPA-mediated activity not involving mGluR5 receptors (O'Leary et al., 2000), this required a dose level orders of magnitude larger than that producing specific mGluR5-mediated effects. It has previously been shown in different areas of the brain that activation of mGluR5 can potentiate NMDA (Doherty et al., 1997; Salt \& Binns, 2000; Mannaioni et al., 2001) and AMPA (Ugolini et al., 1999) responses.

\section{Conclusions}

Whatever the mechanism involved, we would like to emphasize that our data strongly suggest that all of the visual effects obtained were mediated specifically by mGluR5 because, in all those cells studied using both agonist and antagonist, the effect of CHPG was the opposite to that obtained with MPEP. This clearly demonstrates a physiological role for mGluR5 receptors in controlling retinal input and further demonstrates the complexity of metabotropic receptor interactions with excitatory and inhibitory elements in the thalamus. The possibility of a postsynaptic locus of action (possibly via NMDA/AMPA receptors), associated with cortical input, could provide some functional advantage to this system, allowing a double control on the electrophysiological properties of the distal dendrites during situations characterized by a general and diffuse activation, e.g. arousal or, conversely, permitting more restrictive influence during sensory processing, as previously demonstrated for mGluR1 (Rivadulla et al., 2002).

\section{Acknowledgements}

This work was supported by grant BFI2002-3200 from the Spanish Ministry of Science and Technology. Dr Luis Martinez participated in some of the experimental work described here.

\section{Abbreviations}

AMPA, d,l- $\alpha$-amino-3-hydroxy-5- $\alpha$-methyl-4-isoxazolepropionate ; CHPG, (R,S)-2-chloro-5hydroxyphenylglycine ; LGN, lateral geniculate nucleus ; mGluR, metabotropic glutamate receptor ; MPEP, 2-methyl-6-(phenylethynyl)-pyridine ; NMDA, $N$-methyl-d-aspartate 


\section{References}

Alagarsamy, S., Marino, M.J., Rouse, S.T., Gereau, R.W. 4th, Heinemann, S.F. \& Conn, P.J. (1999) Activation of NMDA receptors reverses desensitization of mGluR5 in native and recombinant systems. Nat. Neurosci., 10, 234-240.

Alagarsamy, S., Rouse, S.T., Junge, C., Hubert, G.W., Gutman, D., Smith, Y. \& Conn, P.J. (2002) NMDA-induced phosphorylation and regulation of mGluR5. Pharmacol. Biochem. Behav., 73, 299-306.DOI: 10.1016/S00913057(02)00826-2

Anwyl, R. (1999) Metabotropic glutamate receptors: electrophysiological properties and role in plasticity. Brain Res. Rev., 29, 83-120.DOI: 10.1016/S0165-0173(98)00050-2

Benquet, P., Gee, C.E. \& Gerber, U. (2002) Two distinct signaling pathways upregulate NMDA receptor responses via two distinct metabotropic glutamate receptor subtypes. J. Neurosci., 22, 9679-9686.

Bordi, F. \& Ugolini, A. (1999) Group I metabotropic glutamate receptors: implications for brain diseases. Prog. Neurobiol., 59, 55-79.

Bortolotto, Z.A., Fitzjohn, S.M. \& Collingridge, G.L. (1999) Roles of metabotropic glutamate receptors in LTP and LTD in the hippocampus. Curr. Opin. Neurobiol., 9, 299-304.

Bradley, S.R., Marino, M.J., Wittmann, M., Rouse, S.T., Awad, H., Levey, A.I. \& Conn, P.J. (2000) Activation of group II metabotropic glutamate receptors inhibits synaptic excitation of the substantia Nigra pars reticulata. J. Neurosci., 20, 3085-3094.

Burke, J.P. \& Hablitz, J.J. (1994) Presynaptic depression of synaptic transmission mediated by activation of metabotropic glutamate receptors in rat neocortex. J. Neurosci., 14, 5120-5130.

Chuang, S.C., Bianchi, R., Kim, D., Shin, H.S. \& Wong, R.K. (2001) Group I metabotropic glutamate receptors elicit epileptiform discharges in the hippocampus through PLCbeta1 signaling. J. Neurosci., 21, 6387-6394.

Cleland, B.G., Dubin, M.W. \& Levick, W.R. (1971) Sustained and transient neurones in the cat's retina and lateral geniculate nucleus. J. Physiol. (Lond.), 217, 473-496.

Conn, P.J. \& Pin, J.P. (1997) Pharmacology and functions of metabotropic glutamate receptors. Annu. Rev. Pharmacol. Toxicol., 37, 205-237.

Cox, C.L. \& Sherman, S.M. (2000) Control of dendritic outputs of inhibitory interneurons in the lateral geniculate nucleus. Neuron, 27, 597-610.

Cox, C.L., Zhou, Q. \& Sherman, S.M. (1998) Glutamate locally activates dendritic outputs of thalamic interneurons. Nature, 394, 478-482.DOI: 10.1038/28855

Derrington, A.M. \& Fuchs, A.F. (1979) Spatial and temporal properties of X and Y cells in the cat lateral geniculate nucleus. J. Physiol. (Lond.), 293, 347-364.

Doherty, A.J., Palmer, M.J., Henley, J.M., Collingridge, G.L. \& Jane, D.E. (1997) (RS)-2-chloro-5hydroxyphenylglycine (CHPG) activates mGlu5, but no mGlu1, receptors expressed in CHO cells and potentiates NMDA responses in the hippocampus. Neuropharmacology, 36, 265-267.DOI: 10.1016/S0028-3908(97)00001-4

Dube, G.R. \& Marshall, K.C. (2000) Activity-dependent activation of presynaptic metabotropic glutamate receptors in locus coeruleus. J. Neurophysiol., 83, 1141-1149.

Enroth-Cugell, C. \& Robson, J.G. (1966) The contrast sensitivity of retinal ganglion cells in the cat. J. Physiol. (Lond.), 187, 517-552.

Erisir, A., Van Horn, S.C., Bickford, M.E. \& Sherman, S.M. (1997) Immunocytochemistry and distribution of parabrachial terminals in the lateral geniculate nucleus of the cat: a comparison with corticogeniculate terminals. J. Comp. Neurol., 377, 535-549.

Gasparini, F., Lingenhohl, K., Stoehr, N., Flor, P.J., Heinrich, M., Vranesic, I., Biollaz, M., Allgeier, H., Heckendorn, R., Urwyler, S., Varney, M.A., Johnson, E.C., Hess, S.D., Rao, S.P., Sacaan, A.I., Santori, E.M., Velicelebi, G. \& Kuhn, R. (1999) 2-Methyl-6-(phenylethynyl)-pyridine (MPEP), a potent, selective and systemically active mGlu5 receptor antagonist. Neuropharmacology, 38, 1493-1503.DOI: 10.1016/S0028-3908(99)00082-9

Gereau, R.W. \& Conn, P.J. (1995) Multiple presynaptic metabotropic glutamate receptors modulate excitatory and inhibitory synaptic transmission in hippocampal area CA1. J. Neurosci., 15, 6879-6889.

Glaum, S.R. \& Miller, R.J. (1993) Metabotropic glutamate receptors depress afferent excitatory transmission in the rat nucleus tractus solitarii. J. Neurophysiol., 70, 2669-2672.

Godwin, D.W., Van Horn, S.C., Eriir, A., Sesma, M., Romano, C. \& Sherman, S.M. (1996) Ultrastructural localization suggests that retinal and cortical inputs access different metabotropic glutamate receptors in the lateral geniculate nucleus. J. Neurosci., 16, 8181-8192.

Gubellini, P., Saulle, E., Centonze, D., Costa, C., Tropepi, D., Bernardi, G., Conquet, F. \& Calabresi, P. (2003) Corticostriatal LTP requires combined mGluR1 and mGluR5 activation. Neuropharmacology, 44, 8-16.DOI:

Hamos, J.E., Van Horn, S.C., Raczkowski, D., Uhlrich, D.J. \& Sherman, S.M. (1985) Synaptic connectivity of a local circuit neurone in lateral geniculate nucleus of the cat. Nature, 317, 618-621.DOI: 10.1038/317618a0

Hamos, J.E., Van Horn, S.C., Raczkowski, D. \& Sherman, S.M. (1987) Synaptic circuits involving an individual retinogeniculate axon in the cat. J. Comp. Neurol., 259, 165-192.DOI: 10.1002/cne.902590202

Herrero, I., Miras-Portugal, M.T. \& Sanchez-Prieto, J. (1992) Positive feedback of glutamate exocytosis by metabotropic presynaptic receptor stimulation. Nature, 360, 163-166.DOI: 10.1038/360163a0

Lee, A.C., Wong, R.K., Chuang, S.C., Shin, H.S. \& Bianchi, R. (2002) Role of synaptic metabotropic glutamate receptors in epileptiform discharges in hippocampal slices. J. Neurophysiol., 88, 1625-1633.

Lee, O., Lee, C.J. \& Choi, S. (2002) Induction mechanisms for L-LTP at thalamic input synapses to the lateral amygdala: requirement of mGluR5 activation. Neuroreport, 13, 685-691.DOI: 10.1097/00001756-20020416000030 
Li, H., Ohishi, H., Kinoshita, A., Shigemoto, R., Nomura, S. \& Mizuno, N. (1997) Localization of a metabotropic glutamate receptor, mGluR7, in axon terminals of presumed nociceptive, primary afferent fibers in the superficial layers of the spinal dorsal horn: an electron microscope study in the rat. Neurosci. Lett., 223, 153-156.DOI: 10.1016/S0304-3940(97)13429-2

Lovinger, D.M. \& McCool, B.A. (1995) Metabotropic glutamate receptor-mediated presynaptic depression at corticostriatal synapses involves mGLuR2 or 3. J. Neurophysiol., 73, 1076-1083.

Manahan-Vaughan, D., Herrero, I., Reymann, K.G. \& Sanchez-Prieto, J. (1999) Presynaptic group 1 metabotropic glutamate receptors may contribute to the expression of long-term potentiation in the hippocampal CA1 region. Neuroscience, 94, 71-82.DOI: 10.1016/S0306-4522(99)00266-3

Mannaioni, G., Marino, M.J., Valenti, O., Traynelis, S.F. \& Conn, P.J. (2001) Metabotropic glutamate receptors 1 and 5 differentially regulate CA1 pyramidal cell function. J. Neurosci., 21, 5925-5934.

Martin, L.J., Blackstone, C.D., Huganir, R.L. \& Price, D.L. (1992) Cellular localization of a metabotropic glutamate receptor in rat brain. Neuron, 9, 259-270.DOI: 10.1016/0896-6273(92)90165-A

McCormick, D.A. \& Prince, D.A. (1987) Actions of acetylcholine in the guinea-pig and cat medial and lateral geniculate nuclei, in vitro. J. Physiol. (Lond.), 392, 147-165.

O'Leary, D.M., Movsesyan, V., Vicini, S. \& Faden, A.I. (2000) Selective mGluR5 antagonists MPEP and SIB-1893 decrease NMDA or glutamate-mediated neuronal toxicity through actions that reflect NMDA receptor antagonism. Br. J. Pharmacol., 131, 1429-1437.

Petralia, R.S., Wang, Y.X., Niedzielski, A.S. \& Wenthold, R.J. (1996) The metabotropic glutamate receptors, mGluR2 and mGluR3, show unique postsynaptic, presynaptic and glial localizations. Neuroscience, 71, 949976.DOI: 10.1016/0306-4522(95)00533-1

Pin, J.P. \& Duvoisin, R. (1995) The metabotropic glutamate receptors: structure and functions. Neuropharmacology, 34, 1-26.DOI: 10.1016/0028-3908(94)00129-G

Pisani, A., Gubellini, P., Bonsi, P., Conquet, F., Picconi, B., Centonze, D., Bernardi, G. \& Calabresi, P. (2001) Metabotropic glutamate receptor 5 mediates the potentiation of N-methyl-D-aspartate responses in medium spiny striatal neurons. Neuroscience, 106, 579-587.DOI: 10.1016/S0306-4522(01)00297-4

Rivadulla, C., Martinez, L., Varela, C. \& Cudeiro, J. (2002) Completing the corticofugal loop: a visual role for the corticogeniculate type 1 metabotropic glutamate receptor. J. Neurosci., 22, 2956-2962.

Rivadulla, C., Martinez, L., Grieve, K.L. \& Cudeiro, J. (2003) Receptive field structure of burst and tonic firing in feline lateral geniculate nucleus. J. Physiol. (Lond.), 553, 601-610.DOI: 10.1113/jphysiol.2003.048561

Rodriguez-Moreno, A., Sistiaga, A., Lerma, J. \& Sanchez-Prieto, J. (1998) Switch from facilitation to inhibition of excitatory synaptic transmission by group I mGluR desensitization. Neuron, 21, 1477-1486.DOI: 10.1016/S08966273(00)80665-0

Salt, T.E. \& Binns, K.E. (2000) Contributions of mGlu1 and mGlu5 receptors to interactions with N-methyl-Daspartate receptor-mediated responses and nociceptive sensory responses of rat thalamic neurons. Neuroscience, 100, 375-380.DOI: 10.1016/S0306-4522(00)00265-7

Salt, T.E., Binns, K.E., Turner, J.P., Gasparini, F. \& Kuhn, R. (1999) Antagonism of the mGlu5 agonist 2-chloro-5hydroxyphenylglycine by the novel selective mGlu5 antagonist 6-methyl-2-(phenylethynyl)-pyridine (MPEP) in the thalamus. Br. J. Pharmacol., 127, 1057-1059.

Sanchez-Prieto, J., Budd, D.C., Herrero, I., Vazquez, E. \& Nicholls, D.G. (1996) Presynaptic receptors and the control of glutamate exocytosis. Trends Neurosci., 19, 235-239.DOI: 10.1016/0166-2236(96)10031-X

Schrader, L.A. \& Tasker, J.G. (1997) Presynaptic modulation by metabotropic glutamate receptors of excitatory and inhibitory synaptic inputs to hypothalamic magnocellular neurons. J. Neurophysiol., 77, 527-536.

Schwartz, N.E. \& Alford, S. (2000) Physiological activation of presynaptic metabotropic glutamate receptors increases intracellular calcium and glutamate release. J. Neurophysiol., 84, 415-427.

Shigemoto, R., Kulik, A., Roberts, J.D., Ohishi, H., Nusser, Z., Kaneko, T. \& Somogyi, P. (1996) Target-cell-specific concentration of a metabotropic glutamate receptor in the presynaptic active zone. Nature, 381, 523-525.DOI: $10.1038 / 381523 \mathrm{a} 0$

Shigemoto, R., Kinoshita, A., Wada, E., Nomura, S., Ohishi, H., Takada, M., Flor, P.J., Neki, A., Abe, T., Nakanishi, S. \& Mizuno, N. (1997) Differential presynaptic localization of metabotropic glutamate receptor subtypes in the rat hippocampus. J. Neurosci., 17, 7503-7522.

Spooren, W.P., Gasparini, F., Salt, T.E. \& Kuhn, R. (2001) Novel allosteric antagonists shed light on mglu(5) receptors and CNS disorders. Trends Pharmacol. Sci., 22, 331-337.DOI: 10.1016/S0165-6147(00)01694-1

Turner, J.P. \& Salt, T.E. (2000) Synaptic activation of the group I metabotropic glutamate receptor mGlu1 on the thalamocortical neurons of the rat dorsal lateral geniculate nucleus in vitro. Neuroscience, 100, 493-505.DOI: 10.1016/S0306-4522(00)00280-3

Ugolini, A., Corsi, M. \& Bordi, F. (1999) Potentiation of NMDA and AMPA responses by the specific mGluR5 agonist CHPG in spinal cord motoneurons. Neuropharmacology, 38, 1569-1576.DOI: 10.1016/S00283908(99)00095-7

Wilson, J.R., Friedlander, M.J. \& Sherman, S.M. (1984) Fine structural morphology of identified X- and Y-cells in the cat's lateral geniculate nucleus. Proc. R. Soc. Lond. B Biol. Sci., 221, 411-436. 